\title{
Effects of Ultraviolet Radiations and Sand Storms on the Flashover Voltages of Silicone Rubber Cable Terminations
}

\author{
M. Annaka ${ }^{1}$, L. S. Nasrat ${ }^{2}$, S. M. El-Khodary ${ }^{3}$, S. El-Debeiky ${ }^{3}$ \\ Electrical Installations Department, Arab Contractors Company, Cairo, Egypt ${ }^{1}$ \\ Electrical Power \& Machines Dept., Faculty of Engineering - Aswan University, Aswan, Egypt ${ }^{2}$ \\ Electrical Power \& Machines Dept., Faculty of Engineering - Ain Shams University, Cairo, Egypt ${ }^{3}$
}

\begin{abstract}
This paper presents an experimental work which was carried out to examine the electrical performance of heat shrinkable cable terminations under desert polluted conditions. The ac $(50 \mathrm{~Hz})$ flashover voltage $(\mathrm{kV})$ has been evaluated for heat shrinkable cable terminations under simulated ultraviolet (UV) radiation of different durations and under different doses of artificial sand storm.
\end{abstract}

Keywords: Flashover voltage - Cable terminations - Surface roughness - Electrical characteristics.

\section{INTRODUCTION}

Insulators are devices used to support, separate and/or suspend conductors at $\mathrm{HV}$ insulations. Insulators are widely used in power systems to insulate various electrical parts and connect them mechanically, thus, their degree of performance can directly affect the operation of power systems. Most power system insulators are used in substations and on transmission and distribution lines. They are subjected to atmospheric conditions and other natural outdoor phenomena, while; a wide range of environmental factors and meteorological conditions influence their electrical performance [1].

Porcelain as an insulating material has over one century of service history, while polymer materials have only three decades. Early generation polymer products did not provide the expected service life, and users still have concerns about polymer insulating material performance [2].

Early polymer products did not provide the expected service life, primarily because of inadequate UV, tear or hydrolytic resistance. As a consequence of some initial product failures, many users continue to be concerned about the long-term performance of polymer materials [3]. Cables are somewhat electrically complicated. The basic cable components are the conductor, the electrical insulation (dielectric) and the shielding. There are different types of conductors and insulations. The types of the components are chosen according to the applications specified [4].

Basically, this assembly is a capacitor with radial symmetry. The metallic core maintained at the high potential constitutes inner electrode surrounded by three polymeric layers. The outer electrode connected to earthpotential is protected by the outer layer from external environment [5].

Ultraviolet (UV) radiation is one of the most important problems that electrical insulations are faced with it. The degrading effects of these radiations are accelerated if there is moisture on the polymer's surface.
Thus polymer compounds for use in outdoor environments should be evaluated in the combined presence of UV radiation and humidity $[6,7]$.

Polymeric cable terminations are widely used for a variety of electrical applications and are being produced and used in the Arabic Republic of Egypt. Polymeric cable terminations are finding increasing applications in distribution networks. The electrical properties of such polymers are strongly influenced by environmentally induced degradation mechanisms.

In this work, the effect of ultraviolet radiation on the polymeric insulators was studied. To achieve this objective, dry and wet flashover tests were carried out on cable terminations. As well, the effect of salinity caused by the exposure of these terminations near coast areas and the effects of sand storms were investigated.

Thus, this paper presents a study of the flashover voltage $(\mathrm{kV})$ for cable terminations exposed to the weather conditions such as ultraviolet and sandstorms at different doses. A comparison of the electrical characteristics of virgin and polluted specimens of silicone rubber cable terminations is carried out.

\section{EXPERIMENTAL TECHNIQUES AND PROCEDURES}

\section{A. Samples Material}

Two heat shrinkable cable terminations made of silicone rubber were prepared at the two ends of $1 * 300 \mathrm{~mm}^{2}$ $\mathrm{Cu} . / \mathrm{XLPE} / \mathrm{PVC} \quad 6 / 10 \quad(12 \mathrm{kV})$ cable of $5 \mathrm{~m}$ length according to IEC 60502 .

B. Preparation of Samples

- Simulation of UV Radiation

Two UV-A lamps (black light) were used to simulate the ultraviolet and were installed inside a box, and then cable termination sheds were subjected to UV for different durations (1000, 2000 and 4000 hours) as shown in fig. 1. 


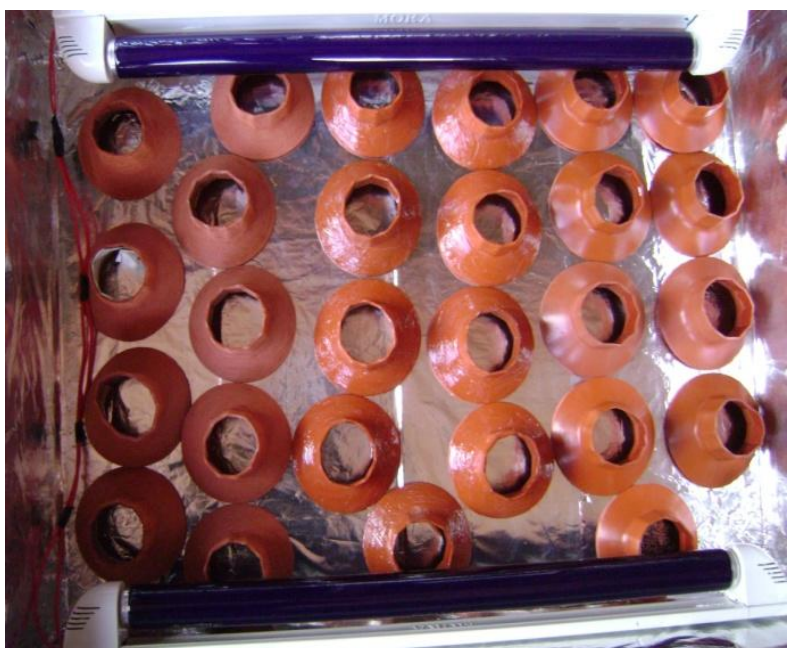

Fig. 1: Photograph of UV device

- Simulation of Sandstrom

To simulate the effect of sand storm on the surfaces of cable termination sheds, they were exposed to continuous artificial sand storm by using abrasive blast cabinet for sand storm simulation in ABB Power System and Automation Technology Company’s Workshop.

The sand grain size was selected to be less than 250 micron to simulate the grain sand of natural sand storm. Cabinet operates under different pressures supplied from variable air compressor with (4-6) bar. The blast system is a venture type, through the design of gun system. Cabinet has glass window to facilitate the observation of specimen's surface inside the device.

Specimens were exposed to artificial sand storm of four different durations (5, 10, 15 and 20 minutes). Surface roughness has been measured for all specimens after each exposure to artificial sand storm by using Optical Interference Microscope. The surface roughnesses of the specimens after the exposure to the four different doses of artificial sand storm were 2.64, 6.36, 9.02 and 13.51 Rmax. $\mu \mathrm{m}$

- Simulation of Coastal Conditions

Then four different solutions were prepared using $\mathrm{NaCl}$ to create salty water having different conductivities (20000, $30000,40000$ and $50000 \mu \mathrm{S} / \mathrm{cm})$.

C. Electrical Test Supply and Test Procedures

The AC high voltage was obtained from a single phase high voltage transformer $(150 \mathrm{kV}-15 \mathrm{kVA})$. The output voltage of the transformer was smoothly controlled by (0$250 \mathrm{~V})$ VARIAC regulating the voltage applied to its primary winding.

A water limiting resistor was connected to the secondary winding of the high voltage testing transformer in order to protect the high voltage transformer from the high current during the tests. The samples were cleaned with tissue to remove dust and other contaminating particles on the surface prior to the test.

According to IEC 1109, power frequency flashover voltage should be determined by averaging five flashover voltages on each specimen.
The diagram representing the testing circuit consists of high voltage testing transformer, water resistance, wiring cable, electrodes and VARIAC regulating panel as shown in fig. 2.

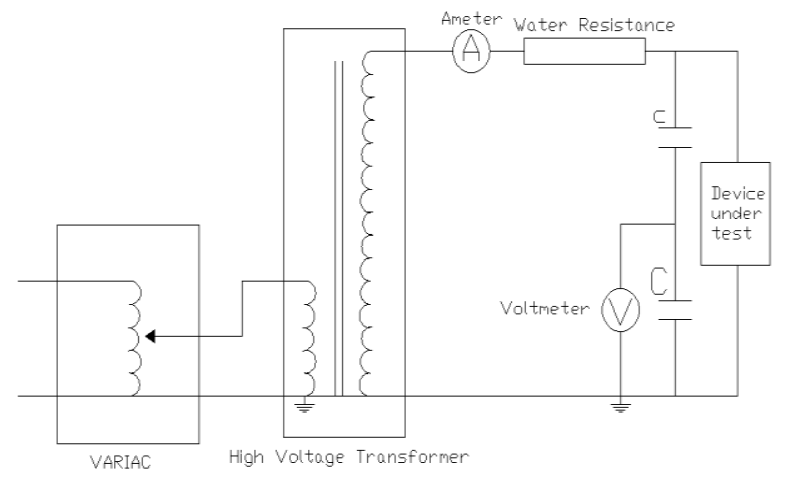

Fig. 2: Schematic diagram of flashover test arrangement

The clamp fixed to the water resistance is manufactured from porcelain which withstands the maximum voltage of testing transformer. And the cross section area of wiring cable was $2 \mathrm{~mm}^{2}$.

Surface flashover tests which show the electrical properties illustrate the behaviour of cable terminations to withstand the voltage applied and these flashover tests were carried out at the HV laboratory of the Faculty of Engineering - Ain Shames University. The researchers studied the practical results of the flashover tests and their performance curves.

Two tests were carried out:

- Dry flashover test: Rated voltage was applied 3 to 5 minutes and then raised until flashover occurs.

- Wet contamination flashover test: The insulators were contaminated by spraying the contaminant mixture. Rated voltage was then applied 3 to 5 minutes after the end of the contamination process while the insulator still wet. Then the test voltage was raised until flashover occurs.

Three sets of cable terminations were tested as follows:

- The first set has been tested dry and then wet at different salinities.

- The second set has been subjected to simulated UV radiation of different doses and then tested dry and then wet at different salinities.

- The third set has been subjected to different doses of artificial sand storm and then tested dry and wet at different salinities

\section{III.RESULTS AND DISCUSSION}

\section{A. Flashover Voltage of Virgin Termination}

The flashover voltage for virgin termination decreases non-linearly from $70 \mathrm{kV}$ at dry condition to $54 \mathrm{kV}$ at wet condition with water conductivity of $50000 \mu \mathrm{S} / \mathrm{cm}$, thus the reduction percentage of flashover voltage is almost $22.8 \%$ as shown in Fig. 3. 


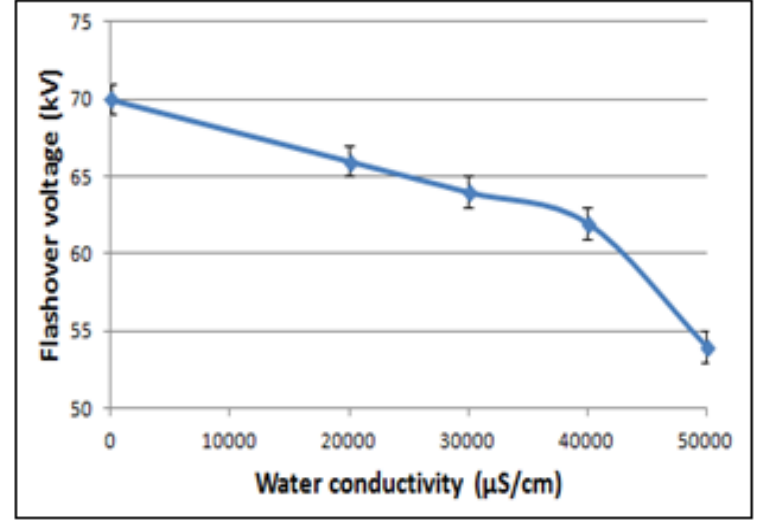

Fig. 3: Flashover voltage $(\mathrm{kV})$ versus water conductivity $(\mu \mathrm{S} / \mathrm{cm})$ for virgin cable termination

\section{B. Effect of Simulated UV Radiation}

Fig. 4 shows a comparison between the effects of different doses of simulated UV radiation on the flashover voltage of cable termination at different water conductivities.

It can be concluded that the value of flashover voltage for cable termination subjected to 1000 hours of simulated $\mathrm{UV}$ radiation at dry condition remained the same at $70 \mathrm{kV}$ as the virgin termination, while it decreased to $53 \mathrm{kV}$ at wet condition with water conductivity of $50000 \mu \mathrm{S} / \mathrm{cm}$. Thus the reduction percentage of flashover voltage compared with the dry virgin cable termination was almost $24.28 \%$.

For the cable termination subjected to 2000 hours of simulated UV radiation, the flashover voltage decreased to $68 \mathrm{kV}$ at dry condition, while it decreased to $51 \mathrm{kV}$ at wet condition with water conductivity of $50000 \mu \mathrm{S} / \mathrm{cm}$. Thus the reduction percentage of flashover voltage compared with the dry virgin cable termination was almost $27.14 \%$ which is slightly higher than the previous case.

For the cable termination subjected to 4000 hours of simulated UV radiation, the flashover voltage decreased to $66 \mathrm{kV}$ at dry condition, while it decreased to $49 \mathrm{kV}$ at wet condition with water conductivity of $50000 \mu \mathrm{S} / \mathrm{cm}$. Thus the reduction percentage of flashover voltage compared with the dry virgin cable termination was almost $30 \%$.

It can be observed that as the exposure time to UV radiation increases the flashover voltage decreases.

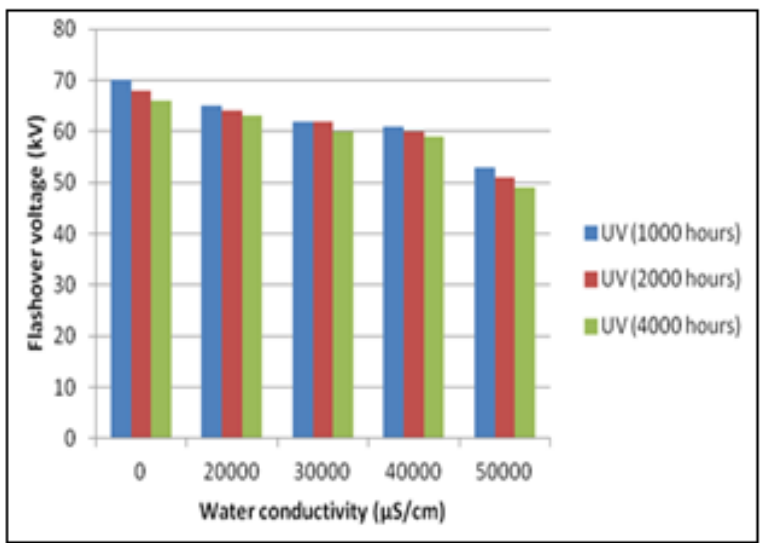

Fig. 4: Comparison between the effects of different doses of simulated UV radiation on the flashover voltage $(\mathrm{kV})$ of cable termination versus water conductivity $(\mu \mathrm{S} / \mathrm{cm})$
This gives an indication that the exposure to the UV radiations decreases the performance and the lifetime of these terminations. This could be due to the effect of UV radiations that degrades the surface of insulator.

\section{Effect of Artificial Sandstorm}

Fig. 5 shows a comparison between the effects of different doses of artificial sand storm on the flashover voltage of cable termination at different water conductivities.

It can be seen that the value of flashover voltage for cable termination subjected to 5 minutes of artificial sand storm at dry condition decreased from $70 \mathrm{kV}$ to $69 \mathrm{kV}$, while it decreased to $50 \mathrm{kV}$ at wet condition of water conductivity of $50000 \mu \mathrm{S} / \mathrm{cm}$. Thus the reduction percentage of flashover voltage compared with the dry virgin cable termination was almost $28.57 \%$.

For the cable termination subjected to 10 minutes of artificial sand storm, the flashover voltage decreased to 68 $\mathrm{kV}$ at dry condition, while it decreased to $49 \mathrm{kV}$ at wet condition of water conductivity of $50000 \mu \mathrm{S} / \mathrm{cm}$. Thus the reduction percentage of flashover voltage compared with the dry virgin cable termination was almost $30 \%$.

For the cable termination subjected to 15 minutes of artificial sand storm, the flashover voltage decreased to 65 $\mathrm{kV}$ at dry condition, while it decreased to $42 \mathrm{kV}$ at wet condition of water conductivity of $50000 \mu \mathrm{S} / \mathrm{cm}$. Thus the reduction percentage of flashover voltage compared with the dry virgin cable termination was almost $40 \%$.

For the cable termination subjected to 20 minutes of artificial sand storm, the flashover voltage decreased to 60 $\mathrm{kV}$ at dry conditions, while it decreased to $40 \mathrm{kV}$ at wet condition of water conductivity of $50000 \mu \mathrm{S} / \mathrm{cm}$. Thus the reduction percentage of flashover voltage compared with the dry virgin cable termination was almost $42.85 \%$.

It can be observed that as the exposure time to sand storm increases the flashover voltage decreases. This gives an indication that the exposure to the sand storm decreases the performance and the lifetime of these terminations. This could be due to the increase of surface roughness caused by exposure to sandstorm.

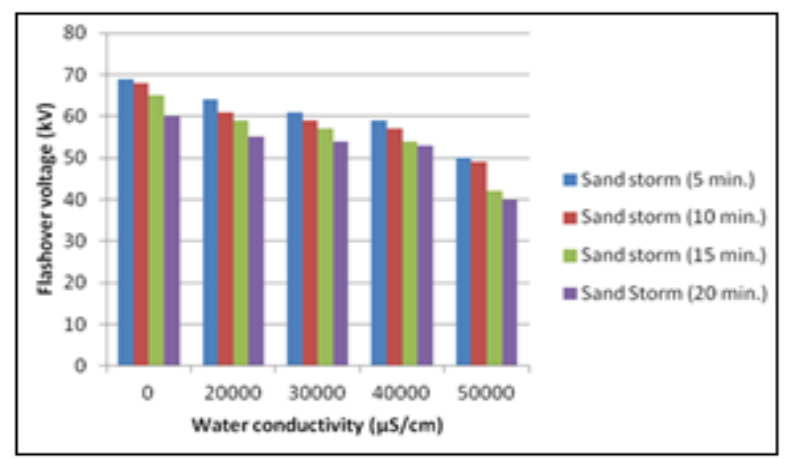

Fig. 5: Comparison between different durations of artificial sand storm on the flashover voltage $(\mathrm{kV})$ of cable termination versus water conductivity $(\mu \mathrm{S} / \mathrm{cm})$

\section{IV.CONCLUSION}

The following conclusions maybe drawn from the present investigation:

A- Weathering conditions such as coastal conditions, radiation and sand storms strongly affect the flashover 
performance of heat shrinkable polymeric cable electrical engineering from Ain Shams University in terminations.

Cairo, Egypt, in 2013. In 2014, He became a member of B- The flashover voltage decreases with the increase of the Ordre des Ingénieurs du Québec (OIQ), Montreal, water conductivity due to the increase in leakage current Quebec, Canada.

and dry band arcing.

$\mathrm{C}$ - The reduction of flashover voltage of cable termination due to the exposure to 1000,2000 and 4000 hours of simulated UV radiation at wet conditions with water conductivity of $50000 \mu \mathrm{S} / \mathrm{cm}$ is $24.28 \%, 27.14 \%$ and $30 \%$ respectively. While the reduction in case of virgin cable termination was $22.8 \%$.

D- The flashover voltages decrease with the increase of the exposure periods to UV and sandstorm due to the increase of surface degradation.

E- The reduction of flashover voltage of cable termination due to the exposure to $5,10,15$ and 20 minutes of artificial sand storm and at wet conditions with water conductivity of $50000 \mu \mathrm{S} / \mathrm{cm}$ is $28.57 \%, 30 \%, 40 \%$ and $42.85 \%$ respectively.

F- The effect of sand storm is more severe than UV radiation on the flashover performance of cable terminations, indicating a more degradation effect.

\section{ACKNOWLEDGMENT}

The authors wish to acknowledge the National Institute for Standards, the Surface Optical Metrology Department for their guidance and encouragement regarding to the measurements of the surface roughness of cable terminations.

\section{REFERENCES}

[1] M. Farzaneh, "Ice Accretions on High Voltage Conductors and Insulators and Related Phenomena", Philosophical Transactions of Royal Society A, Vol. 358, pp. 2971-3005, 2000.

[2] J. Mackevich and M. Shah, "Polymer Outdoor Insulating Materials Part I: Comparison of Porcelain and Polymer Electrical Insulation", IEEE Electrical Insulation Magazine Vol. 13, No. 3, pp. 5 - 12, May/June 1997.

[3] D. Thornley and A. Shocket, "25 Years Experience of Outdoor Polymeric Insulation " Transmission and Distribution Conference, 1994., Proceedings of the 1994 IEEE Power Engineering Society, pp. $67-72,1994$

[4] W. F. Powers, "The Basics of Power Cable", IEEE Transactions on Industry Applications, Vol. 30, No. 3, pp. 506-509, May/June 1994.

[5] C. Brackeniers, A. Cheenne-Astorino, "A New Family of MV Terminations", Power Cables and Accessories 10kV - 500kV, Third International Conference on Power, Energy, and Industry Applications, pp. 135-139, 1993.

[6] Z. Farhadinejad, M. Ehsani, I. Ahmadi-Joneidi and A. A. Shayegani, "Effects of UVC Radiation in Thermal, Electrical and Morphological Behavior of Silicone Rubber Insulators", IEEE Transactions on Dielectrics and Electrical Insulation, vol. 19, no. 5, pp. 1740-1749, 2012

[7] M. Amin and M. Salman, "Aging of polymeric insulators", Advanced Study Center Co. Ltd., pp. 92-116, 2006.

\section{BIOGRAPHIES}

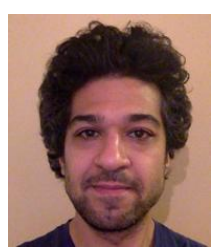

M. Annaka was born in Kuwait in 1984. He received the B.Sc. degree in electrical engineering from Ain Shams University in Cairo, Egypt, in 2007. In January 2008, he joined the Arab Contractors Company, one of the biggest construction companies in the Middle East; as an electrical site engineer. He received M.Sc. degree in 